\title{
Religião e epidemias na história: do essencial ao perverso
}

\section{Religion and epidemics in history: from essential to perverse}

\author{
Mário Antônio Sanches* \\ Ordilei Arcanjo Lovo** \\ Leide da Conceição Sanches***
}

Resumo: Este estudo aborda a relação entre religião e epidemias, buscando posturas recorrentes ao longo da história. Este estudo foi estimulado a partir da indagação: qual a relaçáo entre epidemia e religião? Observa-se que sociedades antigas atribuíam simultaneamente causas naturais e religiosas para as epidemias, que é recorrente na história a ideia de epidemias como castigo e que os grupos indicados como culpados eram os mesmos que já discriminados pela sociedade em questão antes da epidemia. Considera-se que a religião pode desempenhar papéis relevantes no enfrentamento da doença e no incentivo à solidariedade, mas pode também desempenhar papéis maléficos, que levam ao agravamento da crise. Por isso as posturas religiosas nas epidemias oscilam do essencial ao perverso.

Palavras-chave: Epidemias. Religião. Castigo. Sofrimento. Enfrentamento.

Abstract: This study addresses the relationship between religion and epidemics seeking recurrent postures throughout history. This study was stimulated by the question: What is the relationship between epidemic and religion? It is seen that ancient societies attributed both natural and religious causes to epidemics. The idea of epidemics as punishment is also recurrent in history. The groups indicated as guilty were the same ones that were already discriminated in that society before the epidemic. It is concluded that religion can play relevant roles in coping with the disease and encouraging solidarity. However, it can also play harmful roles, which leads to the worsening of the crisis. So, religious attitudes in epidemics oscillate from essential to perverse.

Keywords: Epidemics. Religion. Punishment. Suffering. Coping.

\section{Introduçáo}

Determinados períodos da história - momentos de crise - recolocam a humanidade para uma postura reflexiva, em busca de significado para si mesma e para cada aspecto da vida individual e social. Períodos de epidemias são destacadamente momento de crise, pois, além da morbidade e mortalidade que provocam, trazem consigo outros

* Docente titular nos PPG em Teologia e em Bioética da PUC-PR (Curitiba, PR). Doutor em teologia (IEPG). ORCID: 0000-0002-5794-2272 - contato: m.sanches@pucpr.br

** Docente da UNIR (Porto Velho, RO). Doutor em teologia pela PUC-PR. ORCID: 0000-0003-05769284 - contato: oalovo@gmail.com

*** Docente do PPG em Ensino das Ciências da Saúde das FPP (Curitiba, PR). Doutora em sociologia (UFPR). ORCID: 0000-0002-5832-7132 - contato: leide.sanches@fpp.edu.br 
elementos que agravam a situação desesperadora: carestia (desestruturação da economia) e fome. Assim, é recorrente a visão de que a peste é companheira da morte, da carestia e da fome (Monteano, 1999, p. 171).

Diante de crises decorrentes de epidemias, todos setores da sociedade são desafiados (Freitas; Napimoga; Donalisio, 2020) e, consequentemente, também os setores religiosos. Este artigo visa, portanto, apresentar posturas religiosas que marcam presença em tempos de epidemias. Algumas posturas são valorizadas pela sociedade como um todo, pois facilitam o enfrentamento da situação, e outras posturas são equivocadas, pois agravam a crise, aumentam os casos e estimulam a perseguição e condenaçáo de determinados indivíduos ou grupos (Cortina, 2018). Busca-se, assim, uma releitura das posturas religiosas que impactam na compreensão da pandemia de COVID-19 à luz dos posicionamentos similares em outros períodos de epidemia.

Este estudo foi estimulado a partir de indagaçóes: qual a relação entre epidemia e religião? De que modo a religião impacta na compreensão da epidemia? De que modo as narrativas religiosas do passado marcam posicionamentos atuais? Antes de avançar na busca de posicionamentos religiosos frente às epidemias ao longo da história, é necessário destacar a relevância do tema para a religião.

Epidemias - como momentos de intenso sofrimento, precarização humana e morte - apelam para o cerne da questáo religiosa. O sofrimento não é uma experiência secundária para os seres vivos, mas a sua própria limitação. Falar da morte é falar do momento em que os seres vivos se deparam com a sua barreira final, sua contradição, sua provisoriedade. A morte coloca, no mínimo, duas questóes essenciais: a questão do sentido da existência e do valor da vida humana.

As grandes religiốes, para não dizer todas, apresentam-se como uma resposta para o sofrimento, um sentido para a vida, apesar da realidade empírica da morte. Em todas as religiốes a transcendência é afirmada, e a afirmação da transcendência é a teimosia em dizer que o sentido da existência não se esvai com a morte. Sendo a experiência do sofrimento e da morte fundamentais para as religióes, não se pode ocultar ou negar a relevância da religiáo em tempos de pandemias, como a de COVID-19.

Este artigo lança mão de pesquisa histórica para falar do momento presente, e isto implica o reconhecimento de dois elementos metodológicos: cada evento histórico só pode ser plenamente elucidado se estudado em seu contexto; cada evento histórico é significado a partir de eventos precedentes. Isto justifica lançar mão de episódios do passado para ajudar a compreender o presente, mas isto também aponta para a limitação desta postura metodológica: o passado não se reduz à leitura que dele fazemos na atualidade. Na verdade, é o presente que suscita os elementos que desejamos buscar no passado e, assim, nossa leitura do passado é sempre parcial, sempre uma releitura à luz da experiência atual. Cabe, assim, o cuidado em não inventar narrativas e atribuí-las ao passado, mas sim, buscar as narrativas do passado para elucidar o presente. Para Hanna Arendt, o passado "estirando-se por todo seu trajeto de volta à origem, ao invés de puxar para trás, empurra para frente, e ao contrário do que seria de esperar, é o futuro que nos impele de volta ao passado" (1972, p. 37).

Assim, a perspectiva histórica repousa na compreensão que pode ser considerada comum para historiadores, de que a história não é linear e não trabalha com o estanque, 
e sim com o que é dinâmico na sociedade (Cardoso; Gomes, 2000). Portanto, de modo geral, a história se ocupa em estudar os fenômenos sociais compreendidos em suas dinâmicas temporais. Cuidadoso com a contextualização histórica em suas pesquisas, Florestan Fernandes (1987) afirma que uma dada sociedade, a qual se pretende pesquisar e que está ao alcance do pesquisador, não pode ser compreendida, nem táo abstratamente, nem de modo táo formal e estrutural. Trata-se de se ater ao campo como espaço delimitado e, ao mesmo tempo, procurar "transcender às fronteiras do imediato" (Fernandes, 1987, p. 10).

Desse modo, as ciências da religiáo lançam mão de elementos históricos, visto que tais relatos estão plenos de reflexáo teológica elaboradas para um determinado período e espaço temporal. Também a teologia depende da memória, e é por meio dela que se extrai imagens, gestos e linguagens, necessários para a superação do não familiar. "As experiências e memórias não são nem inertes, nem mortas, elas são dinâmicas e imortais" (Moscovici, 2009, p. 78). A reflexão teológica precisa criticamente lidar com o passado: por um lado, destaca que a religiáo atualiza a experiência vivida; por outro lado, há que mostrar que a experiência vivenciada no passado carrega consigo a cosmovisão das sociedades em questáo.

O desafio da teologia é atualizar a experiência fundamental de cada religião, sem repetir acriticamente as visóes culturais e científicas das sociedades onde elas surgiram. Segundo Brunner (1952, p. 49), há leituras da Bíblia que tentam incluir na figura moderna de tempo e espaço processos que correspondem a figura de tempo e espaço diferentes, e que essas leituras possivelmente não podem reproduzir. Desse modo, essa posição não é "conservadora", mas quixotesca e reacionária, e está atentando ao impossível: combinar visões de tempo e espaço que não podem ser combinadas Essa reflexão de Brunner (1952), construída no contexto do diálogo entre religiáo e ciência, se aplica ao contexto deste artigo, no qual a visão mítica das epidemias em textos sagrados precisa ser compreendida e deixada no passado. Repetir tal visão nos dias atuais é se expor ao ridículo e apregoar irracionalidades. Deveria ser convincente e já claramente aceito que, para ser fiel à revelação do Deus da Bíblia, não é necessário limitar-se aos conhecimentos científicos das pessoas que a escreveram. Quem afirma que aceitar a fé bíblica é apegar-se à visão de mundo que a ciência dos tempos bíblicos permitia está exatamente negando a possibilidade de se crer em Deus nos tempos atuais, visto que esta visão é, hoje, insustentável.

\section{Epidemias na antiguidade: causas naturais e espirituais}

Opta-se por utilizar ao longo do trabalho o termo "epidemia" toda vez que se refere aos diversos episódios que retratam os problemas de saúde de grandes conjuntos humanos no decorrer da história. Entretanto, não se pode perder de vista que no passado utilizava-se o termo "peste" para designar de forma genérica "pestilências" ou "pragas" a exemplo das "pragas do Egito" (Lewinsohn, 2003, p. 41). Com relação aos termos "praga" e "peste", observa-se que as vezes são usados indistintamente para descrever a mesma epidemia, embora o termo "praga" remeta, principalmente, às sociedades ocidentais, marcadas pelo pensamento hebraico no relato bíblico das sete pragas do Egito. 
Na narrativa bíblica, as pragas foram enviadas por Deus contra o Egito, sua liderança e seu povo, para forçar o faraó a deixar o povo de Israel partir sob liderança de Moisés rumo à terra prometida (Êxodo, caps. 7-11). Esse relato, que está longe de ser considerado pelos estudiosos "um registro fotográfico objetivo do que ocorreu" (Anderson, 1968, p. 46), expressa o modo como os israelitas vivenciaram e interpretaram esses fenômenos, e exatamente por isso influenciou a cultura ocidental, marcada pelo pensamento judaico-cristấo. É notável perceber que uma das pragas era uma peste, as outras náo eram pestes, no sentido de doenças, embora todas correspondessem a formas de castigo divino. Essa passagem clássica pode estar sendo evocada em cada fala de religiosos na atualidade que evoca a peste como uma praga, um castigo.

Encontram-se passagens na Bíblia que remetem ao que hoje se poderia chamar de medicina científica, tanto quanto passagens que apresentam as epidemias como forças malignas. O Levítico descreve a lepra com observaçóes rigorosas, que orientam para o caráter "científico" da descriçáo da doença. Os capítulos 13 e 14 desse livro soam como um escrito de natureza médica ao estilo da época (Douglas, 2006, p. 209). Além de descrever a doença, indica-se o tratamento, recomendando-se o isolamento como medida sanitária para náo disseminar a doença: "o sacerdote examinará a chaga na cútis carnosa, e se o pelo na parte infecta houver embranquecido e a parte enferma se apresentar mais funda que o resto da pele, é chaga de lepra. Ao constatar isto, o sacerdote declará-lo-á impuro" (Levítico, cap.13. vs 3).

A importância que o livro dispensou à lepra está retratada na extensão (ocupa dois capítulos inteiros do Levítico) e nos detalhes com os quais é apresentada a doença. Os detalhes são tantos, que hoje se pode identificar uma variedade de doenças sob o termo hebreu "lepra" (Douglas, 2006, p. 210). Desse modo, a lepra é um exemplo claro de como o indivíduo impuro, como culpado que é, passa a ser excluído de todos os lugares públicos e sagrados, como uma forma de expiação, anulação da mancha. Isto posto, deparamo-nos diante da epidemia e sua função desintegradora dos valores morais. A limpeza moral acompanha a limpeza física e a purga dos humores no sentido médico pode simbolizar uma purificaçáo "totalmente moral" (Ricoeur, 2013, pp. 53 e 54).

Além da influência hebraica, o pensamento grego também marca a visão ocidental sobre as epidemias. Isso desde o relato sobre a peste de Atenas de autoria de Tucídides, considerado o melhor dos historiadores gregos do final o século V AEC. A peste de Atenas teria ocorrido no ano de $430 \mathrm{AEC}$, contra a qual "nada podiam fazer os médicos por seu desconhecimento da enfermidade que tratavam pela primeira vez" (Tucídides, 2011, p. 20). Na Grécia, nos séculos V e IV AEC crescia, portanto, concomitantemente com a ideia de causa divina das doenças, a teoria científica racional, que ganha força, mas não destitui os aspectos religiosos e míticos do pensamento médico (Rosen, 1994).

Pascal (2011) destaca a relação "epidemia" e "guerra" como parte da tradiçấo literária grega e as duas podem ser compreendidas como castigo dos deuses. Para o autor, o relato de Tucídides se relaciona de forma direta com os poemas épicos. Deste modo, as imagens de "cáes e aves" disputando os corpos insepultos remetem, no relato da epidemia, à tradição literária anterior a ela, como uma das piores coisas que poderia acontecer a um ser humano, ser privado de um enterro adequado. Para Pascal, a peste de Atenas é reveladora da situação de crise de valores da sociedade grega: "a peste ateniense 
se revela como una autêntica experiência de destruição de valores, uma experiência que a extraordinária força emotiva de Tucídides soube transmitir a leitores de muitas geraçôes" (Pascal, 2011, p.138).

O relato de Tucídides tornou-se um clássico da literatura médica mundial, e o modo como ele descreve os sintomas da doença será inúmeras vezes repetido na literatura que se produz posteriormente. Isto também é percebido na obra de Galeno, Avicena e muitos outros, num contexto de desenvolvimento de racionalidade natural. É interessante observar essa dinâmica que marca o conhecimento humano - no caso em estudo, tanto na medicina como na teologia: um novo episódio é lido e interpretado a partir dos relatos do passado. Sem argumentos novos, as interpretaçóes do passado atropelam e enquadram as novas experiências.

Segundo Fernández (2004), várias ondas de epidemias ocorreram no Império Romano, que era conhecido como tendo boas condiçóes sanitárias. Por isso, as epidemias ocorreram em períodos breves, às vezes com retornos sucessivos. Dentre essas epidemias, a primeira peste Antonina (165 a $170 \mathrm{EC}$ ), foi chamada por alguns também de "peste de Galeno" por ter sido vivenciada e relatada por este médico romano. Galeno relatava em seu Methodus Medendi que essa peste estava presente em Roma em 166, com efeitos devastadores. O termo latino "pestis", ou pestilência, empregado por Galeno, equivale ao grego "loimos", que "corresponde a uma enfermidade grande, frequentemente mortal e que atuava sobre grande número de pessoas" (Gozalbes, García, 2007, p. 7). Galeno descreveu a peste Antonina num registro, entre o clínico e o literário, muito próximo do qual Tucídides descreveu a peste de Atenas:

O médico romano (Galeno) fala expressamente de uma grande inflamação nos olhos, vermelhidão muito forte no interior da boca e da língua, sofrimento do paciente de uma enorme sede, sensação de abrasamento interior, enrijecimento da pele, violentas irrupçōes e fístulas, seguidas de diarreia, esgotamento físico, etc. (Gozalbes, García, 2007, p. 11).

Por fim, observa-se na Antiguidade a identificação de grupos sociais como culpados pelas epidemias. Esse é um elemento recorrente na história das epidemias: identificar um grupo social que seja considerado culpado e responsável pela ocorrência e proliferação das doenças. Assim, as pragas relatadas na Bíblia eram vistas como consequências da desobediência do faraó, e deste modo, os egípcios sofriam as consequência por terem afligido o povo de Israel. No primeiro século do cristianismo, Tertuliano registra uma situação em que os cristãos eram perseguidos, e desta forma, eram considerados culpados de todas as doenças e epidemias que se abatiam sobre a população. "Se o (rio) Tigre transborda... se a fome e a peste chegam então gritam: cristãos aos leões!” (Gozalbes, García, 2007, p. 16). Por outro lado, Ambrósio muda os termos e atribui as epidemias ao fato de os cristãos terem sido perseguidos.

Desse modo, pode-se afirmar que, tanto no pensamento hebraico como no grego, as epidemias estavam duplamente relacionadas às causas naturais e religiosas. Era, por um lado, castigo dos deuses e, por outro, podia ser observada, analisada e evitada com medidas humanas. A degradação moral da sociedade era considerada causa e consequência das epidemias, causadas como castigos dos deuses e que, por sua vez, levavam a humanidade a gestos degradantes. Essas abordagens concomitantes - mítico-religiosa 
e científica - estarão presentes na compreensão das epidemias que vão ocorrer ao longo da história. Curiosamente, mesmo com o advento das ciências biológicas, há lideranças religiosas que continuam apelando para causas espirituais ao explicar eventos como a aids e a COVID-19.

\section{Da peste negra ao século XXI: novos cenários e culpados.}

Para Fernández (2004, p. 87), a expressão "praga negra" ou "peste negra" foi usada pela primeira vez em 1550, após a propagaçáo da epidemia. Se, inicialmente, a epidemia era mais uma peste, o acréscimo do qualificativo "negra" teve um caráter descritivo e simbólico, por causa das manchas escuras que produzia na pele dos infetados, e só serve para designar a epidemia do século XIV. Calcula-se que no período de 1348 a 1350 /1351 tenham morrido entre um quarto e a metade da populaçáo da Europa devido à epidemia (Ruiz de Loizaga, 2009, pp. 23-24). Assim de todas as epidemias ocorridas na Europa até entáo, a peste negra foi a mais assustadora e letal.

No período da propagaçáo da peste negra, era comum a utilizaçáo dos termos febre, infecção, moléstia, todos com o sentido de peste, mas sem menção a esta palavra. Atribui-se o fato de não se pronunciar o nome da doença ou negar-se nomeá-la, a uma superstição corrente na época de que nomeá-la contribui para sua proliferação (Rasia, 1996; Lewinsohn, 2003).

Os mais afetados pela peste negra foram as crianças e os jovens, com alto índice de mortalidade, que variava segundo a forma da doença. Na forma bubônica, o índice de mortes variava de $40 \%$ a $90 \%$ e na forma pulmonar de $90 \%$ a $100 \%$; na forma septicêmica, a morte era certa. Isto porque o complicado mecanismo de transmissão da doença demorou a se tornar conhecido. Não se sabia na época que o bacilo sobrevivia durante alguns dias nos cadáveres e, tampouco, que mesmo que estes fossem enterrados o contágio poderia se dar por meio de roedores que se infiltravam nas covas e também pelas condiçôes gerais das sepulturas e de falta de higiene na manipulação dos corpos infectados.

O bacilo Pasteurella pestis causador da Peste Negra, que era apenas uma de suas variaçóes, só foi isolado em 1894 . O rato portador da pulga vetor do contágio proliferou na Europa a partir do Século XIII e, antes disso, eram encontrados principalmente nas cidades portuárias e com menos frequência na zona rural. $\mathrm{O}$ desenvolvimento do comércio permitiu que os ratos se espalhassem levados em mercadorias como grãos, fardos de lá, peles e tecidos. Para que o ciclo de contágio se completasse, era necessário que as condiçóes climáticas fossem favoráveis, principalmente a umidade e o calor. Por isso, segundo os estudiosos medievais e renascentistas, os grandes picos da peste se davam em regiôes e em épocas de clima mais quente e estaçôes mais chuvosas.

Um dos estudiosos da peste negra, Alfonso de Córdoba (1348), estudado por Amasuno (1997), foi um médico cristáo medieval que viveu na época da peste e presenciou a irrupção da epidemia. Embora Córdoba residisse em Montpellier, na França, escreveu seu tratado sobre a peste na regiáo da Península Ibérica. Seu tratado, em alguns aspectos, apresenta afinidades com o pensamento alemáo, chegando a contribuir com um capítulo na enciclopédia Buch der Natur (Livro da Natureza) do alemão Konrad von 
Megenberg. O ponto de concordância entre a obra de Córdoba e a de Megenberg é a referência que ambos fazem a duas hipóteses etiológicas da peste: a primeira compreende a peste negra como castigo de Deus e a segunda como culpa dos judeus (Amasuno, 1997, pp. 260-271). Assim, tem-se um novo cenário e um novo culpado.

Amasuno (1997), escrevendo sobre o trabalho de Alfonso de Córdoba, aponta que em todos os escritos dos cronistas sobre a peste negra surge uma ou outra explicaçáo religiosa, e que, dada a força gigantesca do desastre por ela provocado, sua intensidade e extensão, só poderiam ser coisa de Deus. O nível de mortalidade da epidemia e a dificuldade de determinar as causas da peste foram cruciais na crença crescente da vontade divina como causadora da peste (Amasuno, 1997, pp. 253 e ss). Ressalta-se que imputar as origens da peste aos judeus implicava a defesa descarada de apoio incondicional aos cristãos, em detrimento da minoria judia. Aqui se percebe uma postura recorrente: o grupo que é apontado como culpado pela epidemia é o grupo já discriminado pela sociedade em questão. Nesse caso, a epidemia serve apenas para intensificar e legitimar a perseguição aos judeus.

A maneira como as explicações sobre a peste se configurava nas crônicas era muito rica em detalhes. Os escritos, especialmente na literatura médica, proliferaram seguindo os picos da epidemia, e resultam do entrelaçamento da medicina greco-árabe com a escolástica. Desse entrelaçamento resulta a concepção cosmológica das causas da peste. A medicina greco-árabe é a principal base do que se poderia chamar de medicina científica medieval. Na verdade, a ausência de explicação sem contradiçóes sobre as causas da peste deixava a sociedade medieval mais confusa e apavorada (Amasuno, 1996, pp. 19-21).

Pavor esse que inspirou Boccaccio (1956), que viveu no tempo da peste negra e escreve sobre a "pestífera mortandade", como ele a considera, e como uma maneira de preparar o leitor sobre as contradiçóes da peste, orienta: "Visto que a dor se situa na extremidade oposta àquela em que a alegria se encontra, evidencia-se que os sofrimentos se concluem no instante em que começa a satisfação superveniente" (Boccaccio, 1956, p. 2).

Segundo Amasuno (1997), qualquer que seja a explicação sobre as causas da peste negra, o que há em comum entre a concepção cristãe e muçulmana é o fatalismo diante da epidemia. Segundo Johannes de Saxônia, autor do "Compêndio de Epidemia na Primeira Metade do Século XV”, muitos cristãos acometidos pela peste se negavam a seguir os conselhos profiláticos porque para eles tratava-se da expiação dos pecados (Amasuno, 1997, p. 265). Desse modo, observa-se uma relação entre enfatizar as causas religiosas das epidemias e uma atitude fatalista: se a doença tem causa divina, cabe à divindade resolver o problema.

Durante a epidemia, a população fugia das cidades para o campo, e a fuga constituía-se numa das formas de se livrar da ameaça que a peste negra representava. Muitos médicos, ao se deparar com pessoas doentes, saíam em fuga. Monteano (1999) cita a declaração de um clérigo, da regiáo de Tudela, que testemunhou a fuga de médicos nos anos de 1530. Numa ata do munícipio de Pamplona, em 1566, consta a destituição de vários médicos de seu ofício, por ter abandonado a cidade, deixando a população sem assistência. Em meio aos sobreviventes, o médico do papa Clemente VI, chamado Guy de Chauliac, em Avignon, na França, relatou que a peste era tâo contagiosa que pais e 
filhos se mantinham afastados por medo da contaminação e que, naquele momento, a caridade desapareceu.

Sobre o medo da contaminação e o abandono dos doentes, encontra-se em Boccaccio (1956) alguns relatos, quando este escreve sobre a proliferação da peste negra na cidade de Florença, expressando as mudanças de comportamento ocorridas pelo impacto da peste naquela sociedade. A fuga dos contaminados é, portanto, constante e acompanha a história das epidemias.

Dessas circunstâncias, e de muitas outras suas semelhantes, ou ainda piores, originavam-se muitos pavores e muitos lances de imaginação nos que continuavam vivos. E quase tudo se orientava para um fim assaz cruel: o de ter nojo e de se fugir dos enfermos e das coisas deles. Assim procedendo, cada qual admitia estar assegurando a saúde para si próprio (Boccaccio, 1956, p. 28).

A consequência da fuga levava ao isolamento dos indivíduos, como forma de "resistir àquele mal" (Boccaccio, 1956, p. 28). $\mathrm{O}$ isolamento podia se dar tanto no ato de náo se desejar nem ouvir falar de morte ou de enfermidade quanto na entrega à diversão como forma de satisfaçáo dos prazeres e até zombar dos acontecimentos. Para os que tinham posses, ainda que abandonados, os acompanhava os "padioleiros", que levavam os caixôes. Para os miseráveis, nenhum cerimonial era mantido - eles poderiam morrer em suas casas das quais eram retirados e colocados sobre tábuas; muitas vezes isto ocorria com famílias inteiras. Não fosse pelo mal cheiro que os cadáveres exalavam, o que levava ao medo de que a putrefação dos corpos lhes fizesse mal, nem mesmo seriam retirados das casas - não era pelo sentimento de caridade que o faziam (Boccaccio, 1956).

Certamente, a peste negra deixou uma marca profunda na memória da humanidade e se torna referência obrigatória para a compreensão de todas as epidemias que a sucedem. Na modernidade, as grandes navegaçóes do século XVI tiveram forte impacto na disseminação das doenças, e especificamente nas Américas, a varíola, o sarampo, o tifo e a disenteria. $\mathrm{O}$ impacto para os nativos das doenças trazidas pelos colonizadores e comerciantes, principalmente a varíola e depois o sarampo, foi um fator importante para a dominação dos indígenas. A disseminação das doenças de um continente a outro se deu em diferentes sentidos. O tráfico de africanos trouxe para a América a febre amarela, a malária e a esquistossomose (Ujvari, 2003, pp. 100-101). A sífilis, por sua vez, surgiu como epidemia no final do século XV em Nápoles e entendeu-se para a Alemanha, França, Suíça, Holanda, Grécia, Inglaterra, Escócia, Hungria e Rússia. Sofreu diversas denominações de acordo com o local onde se disseminava, até que em 1530, quando Fracastoro publicou o poema em latim Syphilis Sive Morbus Gallicus, que retrata a lenda de Sífilo, jovem pastor que insultou Apolo e, por isso, foi punido com a moléstia. Daí em diante, a doença recebe o nome de sifilis (Rosen, 1994, pp. 85-86).

Os tratados sobre as pestes do período moderno insistem na sangria como tratamento, mas continuam apresentando uma visão moralizante. Alonso Diez Daça, na parte do trabalho em que busca explicar "porque alguns mais do que outros sofrem deste mal", cita Avicena e Galeno e inicia com uma avaliaçáo moral:

Os corpos que estão puros e limpos de superficialidades, que não praticam a destemperança, e que tem tido e guardado moderados regimentos em sua vida, em relação à bebida, nas relaçóes com as mulheres, no sono e nos exercícios, estes em tempo de 
pestilências (epidemias) estão seguros e bem preservados....Ao contrário, os muito orgulhosos, viciados, dados a bebida e às mulheres... os que fazem muita crueldade, estes tais serão atingidos por tal enfermidade e delas morrerão (Diez Daça, 1568, p. 8).

Desse modo, o autor afirma que a prevenção é possível e mostra que é parte do ofício do médico organizá-la, e indica o "primeiro e mais principal remédio para prevenir a peste" que é "pedir à divina Majestade misericórdia e perdão dos pecados" (NUNES, 1601 , p. 82). Assim, coerentemente, ele indica ser papel do médico cuidar para que haja penitência e que os doentes sejam encaminhados aos seus confessores.

Em sua obra escrita em Londres em 1729, Richard Mead, membro do College of Physicians and of the Royal Society, recomenda disciplina para evitar que a peste se propague. Ao encontrar-se uma casa infectada, manter fechada, com uma grande cruz vermelha na qual esteja escrito, "Deus tenha misericórdia de nós na porta; um vigia atendendo dia e noite para evitar que alguém entre ou sai, exceto médicos, enfermeiras..." (Mead, 1720, p. 32).

A gripe espanhola ficou dramaticamente famosa ao atingir a Espanha em 1918 e se espalhar por muitos outros países, incluindo o continente americano. Pablo Martinez relata que 1918 haveria um "mítico no setor das pompas funerárias", isto porque depois que terminou a Primeira Guerra Mundial, que matou mais de 10 milhóes de pessoas, surgiu uma epidemia que acabou com "quarenta milhóes de vidas em apenas doze meses" (Zarracina, 1918).

O fato é que as epidemias impactaram nas taxas de natalidade e mortalidade, quando as taxas de natalidade no século XVIII chegaram a variar de 15 a 50 nascimentos em cada mil habitantes, ao passo que em alguns momentos mais críticos a mortalidade chegou a 400 em cada mil habitantes. O papel desempenhado por doenças como cólera, tifo e febre amarela não tiveram impacto somente quando são epidêmicas, pois a forma endêmica destas doenças continua fazendo vítimas em muitos países, contribuindo para as taxas de mortalidade. A importância dessas doenças na contemporaneidade difere em muito do que foi no período compreendido entre os séculos XVII e XIX e mesmo início do século XX (Luis; Castilgione, 2020). O desenvolvimento de recursos farmacológicos como vacinas, antibióticos, antitérmicos modernos, assim como o uso endovenoso do soro para hidratação, melhoraram muito a terapêutica dessas doenças. Associe-se a esses fatores a melhoria, também, das condiçóes de higiene e alimentação da população. Todavia, a ideia de castigo e culpa permanece, como a obra de Albert Camus (2010), que instiga a reflexão sobre a culpa. Trata-se de um romance escrito em 1947 sobre a epidemia que ocorreu na Argélia, na cidade de Oran. Um dos personagens, o jesuíta Paneloux, em seus sermóes, repetia que as pessoas mereciam aquela desgraça.

Traçar as marcas das epidemias no Ocidente leva necessariamente à aids. Aids é a sigla em inglês da acquired imunodeficiency syndrom, provocada pelo vírus do HIV, da classe dos retrovírus. A aids é o conjunto de sintomas da infecção por ele produzidos, que causa danos graves ao sistema imunológico, reduzindo as defesas do organismo e expondo o indivíduo a todo tipo de infecção (doenças oportunistas) e a alguns tipos de câncer.

A aids surpreendeu o mundo, pois na década de 1980 já pairava no ar uma certa segurança de que o desenvolvimento científico, o aprimoramento da medicina, amplas 
coberturas de vacinação e acesso a tratamentos iriam inibir de uma vez por todas o aparecimento de novas epidemias. As causas naturais das doenças estavam desvendadas e a humanidade poderia trilhar seu caminho com a segurança de que doenças contagiosas estavam sob controle. $\mathrm{O}$ surgimento da aids não só colocou em questáo a segurança apregoada pelas ciências, como também deu vazão para as mesmas posturas religiosas do passado: a aids é castigo e há culpados.

No contexto conservador dos Estados Unidos da América, nos anos de 1980, a aids chega como resposta à liberdade sexual conquistada no final dos anos de 1960.

A promiscuidade acabou sendo contida [...] pelo estímulo de dois fatores inesperados: a aids, a terrível doença que ataca preferencialmente os homossexuais, e o vírus do herpes. $\mathrm{O}$ temor a essas doenças, a primeira fatal e a segunda incurável - freou os impulsos em direção a uma excessiva troca de parceiros, e a seu modo ajudou a forjar um país mais de acordo com os ventos conservadores [...] (Revista Veja, 1984, p. 40).

O depoimento da matéria jornalística acima é importante como ponto de partida para situar a aids e o contexto em que surge, nos Estados Unidos. A ideologia conservadora que preponderava naquele momento foi de que os excessos da revolução sexual tiveram uma resposta "inesperada", como se fosse mágica. O modo como a aids foi percebida naquele momento foi crucial para a maneira como sua representação se deu e se dá, pois a ideologia conservadora busca culpabilizar aquele que não se comporta de acordo com os padrōes dominantes. Assim, a aids que ataca primeiramente os homossexuais é vista pelos conservadores como forma de expiaçáo dos pecados, cuja origem está no comportamento sexual não aprovado socialmente.

O fato de a contaminação pelo vírus da aids se dar na maioria dos casos pelo contato sexual acirra a culpabilização. Foi assim com a sífilis, como nos lembra Sontag (2007), que, em algumas cidades, um "sifilítico" poderia ser visto como um depravado. A autora lembra que uma condenação não é necessariamente moral ou religiosa, mas é apontar que há algo errado com o indivíduo.

Cada epidemia, por características próprias, suscita um conjunto de representaçóes mais presentes e mais pertinentes. A aids evocou com muita força temas como homossexualidade, que não estão presentes em outras epidemias. A doença como castigo divino, que perpassa todas as epidemias como visto acima, chega com força no modo como a aids é vista até a descoberta do AZT. Se ao longo da história das epidemias, a "peste" e as "pragas" deflagravam impurezas no seu surgimento, a aids cumpriu a mesma função. Considerada como "peste gay", reforçou a discriminação e os preconceitos contra os homossexuais e a homossexualidade masculina. Decorrente dessa situaçáo, a comunidade médica definia os homossexuais como grupo de risco para a aids, ou seja, determinava quem estava mais sujeito a ser contaminado e disseminar o vírus. $\mathrm{Na}$ medida em que a epidemia atingiu homens heterossexuais, mulheres e crianças, a denominação peste gay, bem como a determinação dos grupos de risco, foram sendo questionadas náo sem as pressóes do movimento gay.

Assim continua-se lançando mão de explicaçôes religiosas para as epidemias do presente momento. Também o ebola chama a atenção, conforme o exemplo contido na seguinte matéria jornalística (Onishi, 2015). Trata-se de uma reportagem sobre a Libéria, que descreve o modo como líderes religiosos locais negavam o vírus e, ou 
simultaneamente, afirmavam que isto era um castigo. $\mathrm{O}$ fundador de uma seita religiosa afirmava que seus membros "tinham o Espírito Santo e que não seriam afetados pelo ebola”. Ao mesmo tempo, praticava-se na seita a imposição das mãos aos doentes que buscavam a cura. Tendo em vista o caráter coletivo do ritual, o contato através da imposição das mãos contribuía para a disseminação do vírus. Como consequência, tais grupos religiosos experimentaram grandes baixas com a morte de muitos membros, incluindo-se nelas a morte do fundador da seita.

\section{Consideraçóes finais}

Observa-se, pelo amplo panorama apresentado, que epidemias e religiáo estiveram sempre relacionadas ao longo da história, como realidades inseparáveis. As epidemias desvendam as fragilidades e provisoriedade humana e isto remete o ser humano a pensar no sentido de sua vida na Terra. Os sentidos poderão ser muitos, mas as religiôes apontam para um sentido transcendente. Esse é o papel fundamental das religiōes, afirmar que a vida faz sentido. É na experiência religiosa do transcendente que a pessoa humana descobre aquilo que McCormick chamou de "palavras poderosas", ou seja, descobre "um novo sentido para a vida" (2000, p. 420).

Decorrente disto, as religióes podem desempenhar em tempos de epidemias papéis relevantes, muito oportunos e valorizados pelas sociedades de todos os tempos. Destacam-se dois aspectos mais relevantes. Primeiramente, preparar as pessoas para um enfrentamento da crise com esperança e serenidade. Esse é o eterno e fundamental serviço que as religióes prestam às sociedades de modo ímpar e insuperável, a certeza de que o momento difícil, o sofrimento e mesmo a morte, não têm a palavra final. Assim, a sociedade acolhe o chamamento religioso, em momento de epidemias, para a reflexão, oração e repensar a vida.

A esperança, fruto da fé, é a virtude humana que é cultivada em ambientes religiosos, como em nenhum outro lugar. Em segundo lugar, brota das religióes o sentido da solidariedade humana também de modo peculiar. Elemento este que promove a convivência entre os povos e o acolhimento e cuidado dos mais fraco (Pedrosa-Pádua, 2020). Nada é mais urgente em tempos de epidemia do que uma solidariedade heroica para acolher e cuidar da grande contingente de enfermos que a doença produz.

$\mathrm{Na}$ Antiguidade se justificava - pela ausência do conhecimento científico em biologia - que uma epidemia fosse vista como originária de causas naturais e espirituais. Predomina entre os grandes líderes religiosos da atualidade uma leitura clara da exata ordem das coisas e as leituras mística das causas das doenças vão sendo deixadas de lado. É parte do conhecimento atual que muitas doenças têm causas múltiplas, que são agravadas por fatores psíquicos e espirituais, entre outros. No entanto, é consenso no interior da maioria das religióes atuais - que a fé não faz o trabalho do bisturi, não substitui vacinas e não imuniza contra vírus e bactérias.

Todavia, alguns líderes religiosos atualmente são levados por uma visão pré-científica da realidade, evocando textos sagrados ou relatos históricos, e se rendem às ideias das causas espirituais das epidemias. Alguns chamam para si a tarefa de invocar o 
transcendente para purgar a doença e realizar exercícios de espiritualidade que exorcizam os vírus, como se estes fossem demônios. Curiosamente, basta ler notícias em tempos de epidemias que exemplos destes tipos povoam os noticiários.

Desse modo, a relação entre religiáo e epidemia se torna perigosa e tais posturas se apresentam como profundamente maléficas para a sociedade e para as próprias religiōes. Para a sociedade, pois desestimula a adesão da população às orientações de autoridades sanitárias, e, além disto, estimula o contato - motivado por pretensa capacidade de cura - que só faz corroborar com o avanço da enfermidade. Será que é tão difícil compreender que os relatos da Antiguidade - presentes também nos textos sagrados - foram escritos a partir da cosmovisão da época? Essa resposta já está dada há mais de meio século por teólogos da estatura de Emil Brunner, como visto acima. Por isso, essa visão de mundo é prejudicial também à religiáo, pois coerentemente implicaria em dizer que ser religioso equivale a não ter uma visão científica de mundo.

A relação entre epidemia e religiáo pode produzir ainda outro comportamento pernicioso: apontar determinados grupos como culpados pela doença. Os fragmentos históricos apresentados acima apontam para a inclinaçáo recorrente de se encontrar culpados para as epidemias. Essas tendências compreendem à divindade como justiceira, que envia doenças para punir culpados. Ao invés de se livrar da ideia antiga de um deus castigador, já há muito superada na maioria das correntes teológicas hodiernas, tais tendências se revelam profundamente discriminadoras e perversas: escolhem para apontar como culpados as pessoas ou grupos sociais que já eram seus inimigos antes da epidemia. Todo amante de uma religião minimamente ética sente-se perplexo diante da postura de um líder religioso que vocifera por décadas contra determinados segmentos da sociedade e que, ao surgir uma epidemia, culpa tais grupos de terem causado a desgraça que assola a todos. Nesse ponto, tristemente, a religião se torna perversa.

\section{References}

AMASUNO SÁRRAGA, Marcelino V. Etiologia del morbo em la Epistola et regimen de pestilentia, de Afonso de Córdoba (1348). Canadá: McGill University, Scriptura 13(1997), pp. 253-275.

ANDERSON, Bernhard W. The living World of the Old Testament. Ed.2. London: Longmans, 1968.

ARENDT, Hannah. Entre o passado e o futuro. SP: Perspectiva, 1972.

BOCCACCIO, Giovanni. O Decamerão. Tradução de Raul de Polillo. Introdução de Edoardo Bizzarri. São Paulo: Livraria Martins Editora, 1956.

BRUNNER, Emil. The christian doctrine of creation and redenption: dogmatics, v. II. London: Lutherworth Press, 1952.

CAMUS, Albert. La Peste. Barcelona: Gallimard, 2010.

CARDOSO, Maria Helena Cabral de Almeida; GOMES, Romeu. Representações 
sociais e história: referenciais teórico-metodológicos para o campo da saúde coletiva. Cad. Saúde Pública, Rio de Janeiro, v. 16, n. 2, pp. 499-506, jun. 2000.

CORTINA, A. Aporofobia, el rechazo al pobre. Un desafio para la democracia. Barcelona/Buenos Aires / México: Paidós, 2018[2017].

DIEZ DAÇA, Alonso. Avisos Y Documentos Para La Preservacion, Y Cura De La Peste. Hechos por el Doctor Alonso Diez Daça. Año de 1568. Publicado em Sevilla: en casa de Clemente Hidalgo, 1599. (Original disponível no Fondo Histórico da Universidade Complutense de Madrid.

DOUGLAS, Mary. El Levítico como literatura: uma investigação antropológica e literária de los ritos em el Antiguo Testamento. Barcelona: Gedisa Editorial, 2006.

FERNANDES, Florestan. A revolução burguesa no Brasil: ensaio de interpretação sociológica. 3. ed. Rio de Janeiro: Guanabara, 1987.

FERNÁNDEZ, Emílio Mitre. Fantasma de la sociedad medieval: enfermedad, peste, muerte. Valladolid: Universidad de Valladolid, 2004.

FREITAS, André Ricardo Ribas; NAPIMOGA, Marcelo; DONALISIO, Maria Rita. Análise da gravidade da pandemia de Covid-19. Epidemiol. Serv. Saúde, Brasília, 29(2):e2020119, 2020. Disponível em: https://www.scielo.br/pdf/ress/ v29n2/2237-9622-ress-29-02-e2020119.pdf. Acessado em 16 de julho de 2020.

GOZALBES, Enrique.; GARCÍA, Inmaculada. La Primera Peste de Los Antoninos (165-170). Una Epidemia En La Roma Imperial. Asclepio. Revista de Historia de la Medicina y de la Ciencia, 2007, vol. LIX, no 1, enero-junio, pp. 7-22.

LEWINSOHN, Rachel. Três Epidemias: lições do passado. Campinas, SP: Editora da UNICAMP, 2003.

LUIS, Natalia; CASTILGIONE, Rosana Aguerregaray. De "culpables" a "víctimas": expansión y profesionalización del sistema de salud en la provincia Mendoza a fines del siglo XIX y principios del XX. Salud Colectiva, 2020;16/e2129/es. Disponível em https://www.scielosp.org/pdf/scol/2020.v16/e2129/es. Acessado em 16 de julho de 2020 .

MCCORMICK, Richard A. Moral theology and the genome project. In: SLOAN, Phillip R., (ed). Controlling our destinies: historical, ethical, and theological perspectives on the Human Genome Project. Notre Dame, IN: University of Notre Dame Press, 2000.

MEAD, Richard. A Short Discourse concerning Pestilential Contagion and the Method to be used to Prevent it. London: Sam. Buckley: 1720. (Original disponível no Fondo Histórico da Universidade Complutense de Madrid.

MONTEANO, Joseba P. Los navarros ante el hambre, la peste, la guerra y la fiscalidad - siglos XV y XVI. Pamplona, Espańa: Universidad Pública de Navarra, 1999. 
MOSCOVICI. Serge. Representações Sociais: investigações em psicologia social. 6 ed. Petrópolis, RJ: Ed. Vozes, 2009.

ONISHI, Norimitsu. Liberia Conquers Ebola, but Churches Face Crisis of Faith. The New York Times International Weekly. Saturday, May 16, 2015.

PASCAL, Amanda Ledesma. Realidad histórica y metáfora política en Tucídides: la descripción de la "peste" en "La Guerra del Peloponeso". (Tese de doutorado). Madrid: UCM, 2011.

PEDROSA-PÁDUA, Lucia. Da indiferença e da aporofobia à hospitalidade: uma reflexão antropológica diante da crise migratória. Rev. Pistis Prax., Teol. Pastor., Curitiba, v. 12, n. 1, pp. 05-25, jan./abr. 2020. Disponível em: https://periodicos. pucpr.br/index.php/pistispraxis/article/view/25563/24190. Acessado em 16 de julho de 2020.

RASIA, José M. Hospital - sociabilidade e sofrimento. 214 f. Tese. Setor de Ciências Humanas, Letras e Artes, Universidade Federal do Paraná: Curitiba. 1996.

RICOEUR, Paul. A simbólica do mal. Lisboa. Portugal: Edições 70, 2013.

ROSEN, George. Uma História da Saúde Pública. São Paulo: Hucitec: Editora da Universidade Estadual Paulista; Rio de Janeiro: Associação Brasileira de PósGraduação em Saúde Coletiva, 1994.

RUIZ DE LOIZAGA, Saturnino. La Peste en Los Reinos Peninsulares según documentación del archivo vaticano (1348-1460). Bilbao, Espanha: Museo Vasco de la Medicina y de la Ciencia, 2009.

TUCÍDIDES. La peste em Atenas. In: RIQUER, Martin de, RIQUER, Borja de. Reportajes de la Historia. Vol I. Barcelona: Acantilado, 2011, p. 20.

UJVARI, Stefan Cunha. A história e suas epidemias: a convivência do homem com os microorganismos. Rio de Janeiro: Editora Senac Rio: Editora Senac São Paulo, 2003.

ZARRACINA, Pablo Martinez - La gripe, el gran virus - El Correo - Madrid - 1918

Recebido: 21 de abril de 2020.

Aprovado: 29 de julho de 2020. 